\title{
Is thymoquinone an antioxidant?
}

\author{
Katrin Staniek ${ }^{*}$ Lars Gille \\ From 16th Scientific Symposium of the Austrian Pharmacological Society (APHAR) \\ Vienna, Austria. 25-27 November 2010
}

\section{Background}

Thymoquinone is one of the active ingredients of black cumin (Nigella sativa L.) essential oil possessing antiinflammatory, antineoplastic, neuro- and hepatoprotective properties. Some of these properties were attributed to an antioxidant activity of thymoquinone, which seems to be unlikely from its structure. Because the lipophilic thymoquinone exhibits a structural similarity with the natural mitochondrial electron carrier, ubiquinone, it was of interest whether the suggested antioxidant effect of thymoquinone in cells can be explained by its interaction with the mitochondrial respiratory chain.

\section{Materials and methods}

Antioxidant activities were determined spectrophotometrically by means of the 2,2-diphenyl-1-picrylhydrazylradical $\left(\mathrm{DPPH}^{*}\right)$ assay $(516 \mathrm{~nm})$ as well as by the $\mathrm{O}_{2}{ }^{*}$ ${ }^{-}$-dependent xanthine / xanthine oxidase / cytochrome c assay $(550 \mathrm{~nm})$. NADH and succinate:thymoquinone oxidoreductase activities of KCN-blocked $(1 \mathrm{mM})$ submitochondrial particles $(0.01 \mathrm{mg} / \mathrm{ml})$ from bovine heart were determined at 340 and $257.5 \mathrm{~nm}$, respectively.

\section{Results}

With the $\mathrm{DPPH}^{*}$ assay thymoquinone was shown to be hardly antioxidative. In contrast, thymohydroquinone was even more active than the vitamin $\mathrm{E}$ analogon pentamethylchromanol (rate constants for the reaction with $\mathrm{DPPH}^{*}: 283.7 \pm 1.9 \mathrm{M}^{-1} \mathrm{~s}^{-1}$ (3) vs. $236.2 \pm 4.7 \mathrm{M}^{-1} \mathrm{~s}^{-1}$ (6); data are means \pm SEM (n). The cytochrome c system turned out to be unsuitable for the evaluation of the antioxidant activity of thymoquinone. Thymoquinone concentration-dependently $(20-1000 \mu \mathrm{M})$ stimulated the NADH $(150 \mu \mathrm{M})$ oxidation of submitochondrial particles to $V_{\max }$ values of around $400 \mathrm{nmol}$ per min per $\mathrm{mg}$ protein. $K_{M}$ values were $77.4 \mu \mathrm{M}$ for thymoquinone and $6.4 \mu \mathrm{M}$ for $\mathrm{NADH}$. The thymoquinone-stimulated $\mathrm{NADH}$ oxidation was sensitive to inhibitors of the mitochondrial electron transfer $(90 \%$ inhibition with $0.2 \mu \mathrm{M}$ rotenone, $49 \%$ inhibition with $1 \mu \mathrm{M}$ antimycin $\mathrm{A}, 82 \%$ inhibition with $1 \mu \mathrm{M}$ antimycin $\mathrm{A}+1 \mu \mathrm{M}$ myxothiazol; $100 \mu \mathrm{M}$ thymoquinone). In addition to its stimulatory effect on NADH:quinone oxidoreductase, thymoquinone $(50 \mu \mathrm{M})$ was reduced to its hydroquinone by rotenone$(0.2 \mu \mathrm{M})$ and $\mathrm{KCN}$-inhibited submitochondrial particles when succinate $(10 \mathrm{mM})$ was used as substrate. This reduction was sensitive to antimycin A and myxothiazol, inhibitors of mitochondrial complex III.

\section{Conclusions}

Thymoquinone (oxidized form) possesses a very low antioxidant activity while its reduced form (thymohydroquinone) exerts a high radical-scavenging capacity, comparable to that of pentamethylchromanol, a short-chain tocopherol analogon. We assume that the mitochondrial respiratory chain is significant for the antioxidant properties of thymoquinone in the cell by converting the administered thymoquinone into its hydroquinone.

Published: 16 November 2010

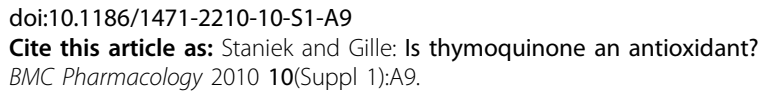

\footnotetext{
* Correspondence: katrin.staniek@vetmeduni.ac.at Molecular Pharmacology and Toxicology Unit, Department of Biomedical Sciences, University of Veterinary Medicine, 1210 Vienna, Austria
} 